\title{
Catatan Marga Centratherum (Asteraceae: Vernonieae) di Pulau Jawa
}

\author{
Arifin Surya Dwipa Irsyam ${ }^{1}$, Arieh Mountara², Asih Perwita Dewi ${ }^{3}$, Muhammad Rifqi Hariri, \\ Surianto Effendi ${ }^{5}$, Rina Ratnasih Irwanto ${ }^{6}$ \\ ${ }^{1}$ Herbarium Bandungense (FIPIA), Sekolah Ilmu dan Teknologi Hayati (SITH), Institut Teknologi Bandung, \\ Labtek VC, Jl. Let. Jen. Purn. Dr (HC) Mashudi No. 1, Sumedang \\ ${ }^{2}$ Departemen Biologi, Fakultas Matematika dan Ilmu Pengetahuan Alam, IPB Univeristy, Dramaga, Bogor \\ ${ }^{3}$ Divisi Botani, Pusat Penelitian Biologi, Lembaga Ilmu Pengetahuan Indonesia, Jl. Raya Bogor KM 46, \\ Cibinong \\ ${ }^{4}$ Pusat Penelitian Konservasi Tumbuhan dan Kebun Raya, Lembaga Ilmu Pengetahuan Indonesia, Jl. Ir. H. \\ Juanda No. 13, Bogor \\ ${ }^{5}$ Divisi Botani, Yayasan Generasi Biologi Indonesia (Genbinesia), Jl. Swadaya Barat No. 4, Semampir, \\ Cerme, Gresik \\ ${ }^{6}$ Sekolah Ilmu dan Teknologi Hayati (SITH), Institut Teknologi Bandung, Labtek XI, Jl. Ganeca No. 10, \\ Bandung \\ E-mail: arifin@sith.itb.ac.id
}

\section{A note on the genus Centratherum (Asteraceae: Vernonieae) in Java}

\begin{abstract}
Asteraceae has the highest number of species with as many as $\pm 30,000$ species are distributed globally, and 150 of them are found in the Malesia region. The species of Asteraceae in Java are recorded in the book Flora of Java Volume 2. However, in recent years, several newly recorded species have been reported in Java. This study aims to uncover a newly recorded plant species to complement the preparation of Alien Flora of Java. This research was conducted using the explorative method from March 2019 to August 2020 at several locations in Java. A newly recorded species of Asteraceae, namely Centratherum punctatum, has been found in Galonggong Village, Bojong Gede Subdistrict (Bogor Regency) and Hegarmanah Village, Jatinangor Subdistrict (Sumedang Regency). The species grows in wild population and it has not been previously recorded in the Flora of Java. Thus, the species addsup the species number of Centratherum in Java. The species description, photographs and brief discussions are provided.
\end{abstract}

Keywords: Asteraceae, Centratherum punctatum, Java, new record, Vernonieae

\begin{abstract}
Abstrak
Suku Asteraceae merupakan suku dengan jumlah jenis tertinggi dan perawakan yang bervariasi. Sebanyak \pm 30.000 jenis tersebar di dunia dan 150 marga di antaranya tersebar di kawasan Malesia. Jenis-jenis Asteraceae di Pulau Jawa tercatat dalam buku Flora of Java Jilid 2. Namun, pada beberapa tahun terakhir jenis-jenis rekaman baru telah dilaporkan dari Jawa. Penelitian ini bertujuan untuk mengungkap jenis tumbuhan rekaman baru sebagai bagian dari penyusunan buku Alien Flora of Java. Penelitian ini dilakukan dengan metode jelajah pada Maret 2019 hingga Agustus 2020 di beberapa lokasi di Pulau Jawa. Satu jenis tumbuhan rekaman baru dari suku Asteraceae, yakni Centratherum punctatum, telah dikoleksi dari Desa Galonggong, Kecamatan Bojong Gede (Kabupaten Bogor) dan Desa Hegarmanah, Kecamatan Jatinangor (Kabupaten Sumedang). Jenis tersebut ditemukan tumbuh meliar dan belum tercatat sebelumnya dalam Flora of Java. Dengan demikian, jenis ini menambah jumlah jenis Centratherum yang terdapat di Jawa. Deskripsi jenis, foto, dan diskusi singkat dipaparkan dalam tulisan.
\end{abstract}

Kata kunci: Asteraceae, Centratherum punctatum, Jawa, rekaman baru, Vernonieae 


\section{Pendahuluan}

Suku Asteraceae (Compositae) merupakan salah satu suku dengan jumlah jenis tertinggi. Suku ini memiliki perawakan yang bervariasi mulai dari terna, semak, perdu, pohon, hingga liana (Laurent, 2016). Persebaran Asteraceae cukup luas dan dapat dijumpai secara kosmopolitan hampir di seluruh belahan dunia, terkecuali di daerah Antartika (Funk et al., 2009; Laurent, 2016; Hind, 2015; Christenhusz et al., 2017). suku Asteraceae terdiri dari \pm 1700 marga dan \pm 30.000 jenis Asteraceae (Funk et al., 2009; Hind, 2015), dan 150 marga di antaranya tersebar di kawasan Malesia (van Steenis, 1987).

Catatan lengkap jenis-jenis tumbuhan dari suku Asteraceae, khususnya di Pulau Jawa, telah terekam dalam buku Flora of Java Jilid 2 (Backer \& Bakhuizen van den Brink, 1965). Berdasarkan referensi tersebut, Pulau Jawa memiliki sebanyak 227 jenis yang tercakup ke dalam 107 marga (Backer \& Bakhuizen van den Brink, 1965). Akan tetapi, sejak empat tahun terakhir, keberadaan jenis rekaman baru untuk Flora of Java telah banyak dilaporkan dari Pulau Jawa (Irsyam \& Hariri, 2016; Tjitrosoedirdjo \& Wahyuni, 2018; Irsyam \& Irwanto, 2019; Irsyam et al., 2020). Hal tersebut karena sebagian anggota suku Asteraceae merupakan komoditas tanaman hias yang diperdagangkan antar pulau di Indonesia serta antar negara (Tjitrosoedirdjo, 2005; Irsyam \& Irwanto, 2019). Selain itu, jenis rekaman baru seperti Praxelis clematidea juga terintroduksi secara tidak sengaja ke Jawa sebagai kontaminan pada kelapa sawit (Tjitrosoedirdjo \& Wahyuni, 2018).

Jenis-jenis tumbuhan Asteraceae yang baru terdaftar untuk Flora of Java, baik sebagai tanaman hias pekarangan maupun jenis yang telah lolos kultivasi, antara lain Eupatorium capillifolium (Lam.) Small ex Porter \& Britton (Irsyam \& Hariri, 2016); Caputia scapose (DC.) B. Nord. \& Pelser, Caputia tomentosa (Haw.) B. Nord. \& Pelser, Curio kleiniiformis (Suess.) L.V.Ozerova \& A.C. Timonin, Curio rowleyanus (H. Jacobsen) P.V. Heath, Kleinia petraea (R.E.Fr.) C. Jeffrey, Senecio macroglossus DC., Senecio tamoides DC., Gymnanthemum amygdalinum (Delile)
Walp., Tarlmounia elliptica (DC.) H. Rob. S.C. Keeley, Skvarla \& R.Chan (Irsyam \& Irwanto, 2019); Praxelis clematidea (Griseb.) R.M.King \& H.Rob. (Tjitrosoedirdjo \& Wahyuni, 2018); dan Pseudogynoxys cabrerae H. Rob. \& Cuatrec. (Irsyam et al., 2020). Keberadaan jenis-jenis tumbuhan introduksi rekaman baru dari suku Asteraceae diduga masih akan terus bertambah, karena anggota suku ini mampu beradaptasi dengan baik di daerah sebaran barunya (Wu \& Wang, 2005). Beberapa jenis tumbuhan Asteraceae introduksi bahkan telah ditetapkan sebagai tumbuhan asing invasif yang penting di Indonesia (Tjitrosoedirdjo, 2007; Tjitrosoedirdjo et al., 2016). Struktur papus pada buah longkahnya juga membantu Asteraceae untuk menyebar luas (Andersen, 1993; Seale \& Nakayama, 2020).

Centratherum merupakan salah satu marga dari Asteraceae yang terdapat di Pulau Jawa (Backer \& Bakhuizen van den Brink, 1965; van Steenis, 1972). Pulau ini memiliki satu jenis endemik yaitu Centratherum frutescens (Bl.) Clarke. Jenis tersebut tumbuh di daerah pegunungan, mulai dari Jawa Barat hingga ke arah timur ke Gunung Sindoro (Backer \& Bakhuizen van den Brink, 1965; van Steenis, 1972). Herbarium Bogoriense (BO) juga menyimpan jenis tersebut sebagai salah satu koleksinya. Penelitian ini bertujuan untuk memberikan informasi terkini mengenai keberadaan jenis Centratherum lainnya di Jawa, yaitu Centratherum punctatum Cass., yang belum pernah terdokumentasikan sebelumnya. Selain itu, penelitian ini juga dilakukan sebagai bagian dari penulisan Alien Flora of Java.

\section{Metode Penelitian}

Penelitian dilakukan pada bulan Desember 2019 hingga Agustus 2020 di Jawa Barat (Dramaga-Bogor, Bandung, dan Sumedang) dan Jawa Timur (Surabaya dan Pulau Madura). Sementara itu, pengamatan di Desa Galonggong, Kecamatan Bojong Gede, Bogor, telah dilakukan sebelumnya pada bulan Maret 2019. Pengamatan lapangan dilakukan menggunakan metode jelajah (Rugayah et al., 2004) dengan fokus area penelitian di lingkungan urban, seperti taman 
kota, kawasan kampus, ladang, dan kebun. Pengambilan sampel mengikuti van Balgooy (1987), yakni sampel berupa satu individu utuh yang memiliki organ vegetatif dan generatif. Sampel dari lapangan selanjutnya diawetkan menjadi spesimen herbarium mengikuti Djarwaningsih et al. (2002) di Herbarium Bandungense (FIPIA), Sekolah Ilmu dan Teknologi Hayati, Institut Teknologi Bandung. Studi herbarium dilakukan di Herbarium Bogoriense (BO) pada bulan Agustus 2020. Referensi yang digunakan untuk proses identifikasi yaitu Backer \& Bakhuizen van den Brink (1965), Kirkman (1981), Bean (2004), dan Ghafoor (2015). Sementara itu, terminologi mengacu pada Beentje (2010).

\section{Hasil Penelitian dan Pembahasan}

Centratherum punctatum Cass., Diet. Sei. Nat. 7: 384. 1817; Kirkman, Rhodora 83(833): 15. 1981; Bean, Austrobaileya 6(4): 977. 2004; Ghafoor, Fl. Australia 37(1): 179. 2015. Type: Brazil: Maran häo: Loretto, Eiten 4042 SP (neo: SP; isoneo: BRI, G, NY, US), fide K.Kirkman, Rhodora 83(833): 15. 1981. (Gambar 1-2).

Ampherephis aristata Kunth, Nov. Gen. Sp. 4: 31. 1820. Type: none cited. Bonpland s.n. (lecto: P; isolecto: P), fide K.Kirkman, Rhodora 83(833): 17. 1981. Centratherum australianum (K.Kirkman) A.R.Bean, Austrobaileya 6(4): 977. 2004. Centratherum punctatum subsp. australianum K.Kirkman, Rhodora 83(833): 21. 1981. Type: New South Wales. North Coast: West of Wingham on Bulga Road, 12 April 1953, J. Vickery 23846 (holo: NSW; iso: L, MO).

Centratherum brachylepis Sch.Bip. ex Baker, Fl. Bras. 6(2); 12. 1873. Type: Brazil, Martius 461 (lecto: M; para: K; isopara: G, GH, LE), fide K.Kirkman, Rhodora 83(833): 18. 1981.

Centratherum holtoni Baker, Fl. Bras. 6(2): 12. 1873. Type: Brazil: Ibague, Holton 301 (holo: K).

Centratherum punctatum var. foliosum Chodat, Bull. Herb. Boissier 2(2): 298. 1902. Type: Paraguay: Capibuy, Hassler 4378. (lecto: BM; isolecto: G, K, NY, P), fide K.Kirkman, Rhodora 83(833): 18. 1981.
Centratherum punctatum var. parviflorum Baker, Fl. Bras. 6(2): 12. 1873. Type: Brazil: Bahia, Blanchet 3689 (lecto: K; isolecto: BR, F, G, LE, MO, P), fide K.Kirkman, Rhodora 83(833): 18. 1981.

Terna, bagian bawah berkayu, tegak atau menanjak, tinggi hingga $1 \mathrm{~m}$. Batang hijau hingga ungu, bersusuhan. Daun tunggal, berseling; daun duduk atau bertangkai pendek; helaian membundar telur hingga menjorong atau menyudip, $3-5 \times 1.6-2.5 \mathrm{~cm}$, pangkal daun membaji hingga menirus, tepi daun menggergaji hingga menggergaji ganda, bersilia, ujung daun membundar, permukaan adaksial dan abaksial berbulu balig. Perbungaan bonggol, terminal, soliter atau mengelompok dalam 2 perbungaan, kuncup perbungaan membulat tertekan, diskoid; diameter c. $1 \mathrm{~cm}$; diameter perbungaan mekar 2-2.5 cm; hanya terdiri dari bunga tabung; gagang perbungaan 2-5 cm, bersusuhan; daun pembalut memangkuk; filari tersusun menyirap, dimorfis; filari terluar berbentuk seperti daun, menjorong hingga membundar telur sungsang, 5-17 × 2$10 \mathrm{~mm}$, tepi menggergaji, hijau, berbulu balig; filari bagian dalam mendelta hingga melonjong, 4-7 × 1-2 mm, menyelaput, bergaris hijau di bagian tengah, ujung keunguan. Bunga tabung: banyak, banci, panjang hingga $12 \mathrm{~mm}$, bersimetri radial; bakal buah melonjong, panjang c. $1 \mathrm{~mm}$, hijau kekuningan; tabung daun mahkota sempit, panjang c. 4-5 mm, melekuk, ungu pucat, berkelenjar; leher daun mahkota c. $1 \mathrm{~mm}$, putih; cuping daun mahkota 5 , memita, $2 \times 0.5$ $\mathrm{mm}$, ungu; tangkai sari membenang, putih, menempel pada daun mahkota; embelan kepala sari menyegitiga, putih; kepala sari 5 , memita, kuning kecokelatan, panjang c. 2-2.5 $\mathrm{mm}$; tangkai putik lebih panjang dari daun mahkota, lengan tangkai putik 2 , melekuk ke dalam, bagian bawah putih, ujung keunguan. Papus berbentuk bulu kejur, krem, panjang 1.5-3.5 mm, luruh. Buah longkah, menyilindris, c. $2 \mathrm{~mm}$, berusuk 8-10, cokelat, gundul.

Sebaran: Secara alami, C. punctatum tersebar di kawasan Neotropis, mulai dari Amerika Tengah, Amerika Selatan, hingga Hindia Barat (Kirkman, 1981; Ghafoor, 2015; RedondaMartínez, 2017). Jenis tersebut kemudian ternaturalisasi di Asia, Afrika, Australia, 
Madeira, Kepulauan Canaria, dan Kepulauan Pasifik (Bean, 2004; Space et al., 2009; Imada, 2012; Ghafoor, 2015; Otto \& Verloove, 2016; Debnath et al., 2017; Timberlake et al., 2020). Habitat: Pada derah sebaran aslinya, jenis ini tumbuh di padang rumput dan lahan marginal (Kirkman, 1981). Pada penelitian ini, C. punctatum ditemukan di sekitar ladang, tepi jalan, kawasan kampus, dan daerah terbuka.

Spesimen yang diamati: Bogor: tepi jalan, Desa Galonggong, dekat basecamp Ciliwung Herpetorium, Kecamatan Bojong Gede, 29 Maret 2019, S Effendi s.n. (FIPIA). Sumedang: Jembatan Cincin, Desa Hegarmanah, Kecamatan Jatinangor, Sumedang, 26 Agustus 2020, ASD Irsyam \& A Mountara 05 (FIPIA). Spesimen lainnya tidak ditemukan di BO.

Nama lokal: tidak terekam.

Pemanfaatan: Jenis ini sering dibudidayakan sebagai tanaman hias (Kirkman, 1981; Chong et al., 2009; Debnath et al., 2017).

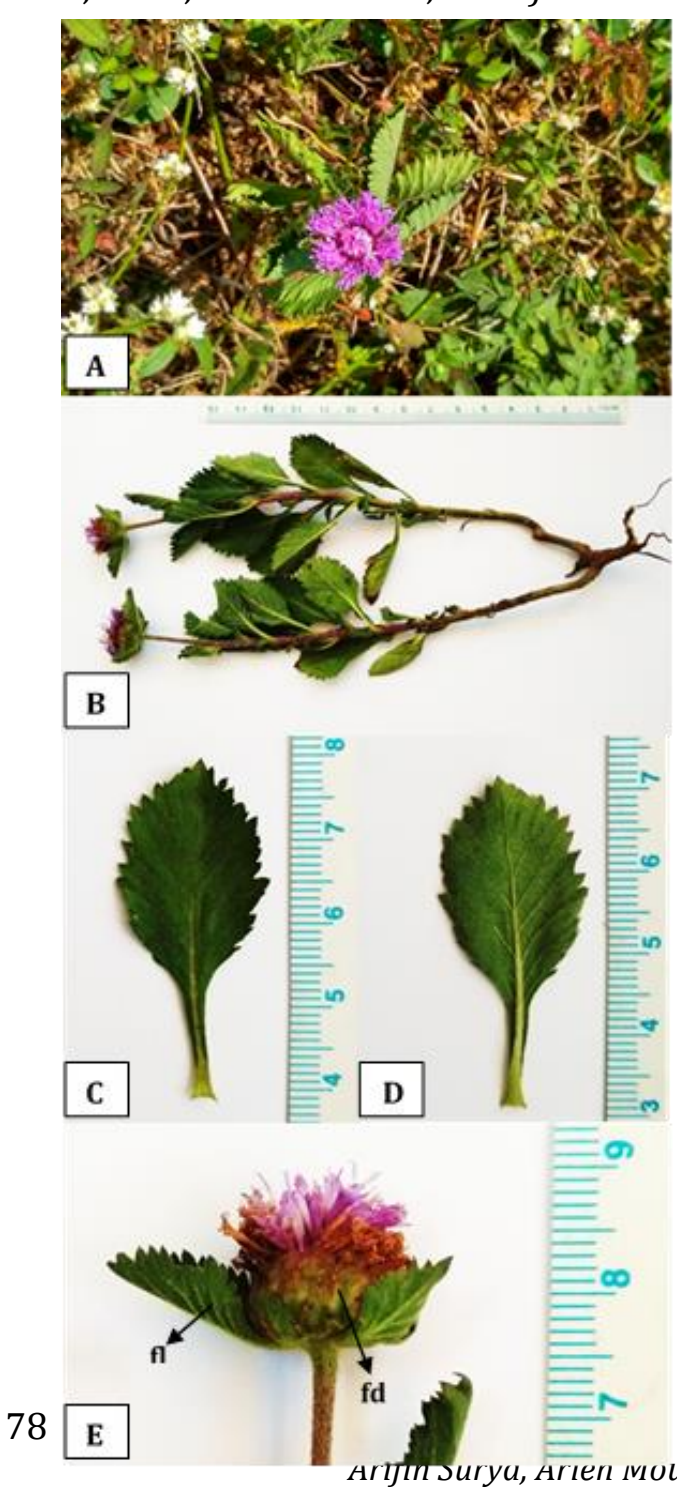

Gambar 1. Centratherum punctatum Cass.

Keterangan: (A) Individu dari populasi meliar di Jatinangor, (B) Individu dengan organ lengkap, (C) Permukaan adaksial daun, (D) Permukaan abaksial daun, dan (E) Perbungaan ( $\mathrm{fl}=$ filari luar; $\mathrm{fd}=$ filari dalam).

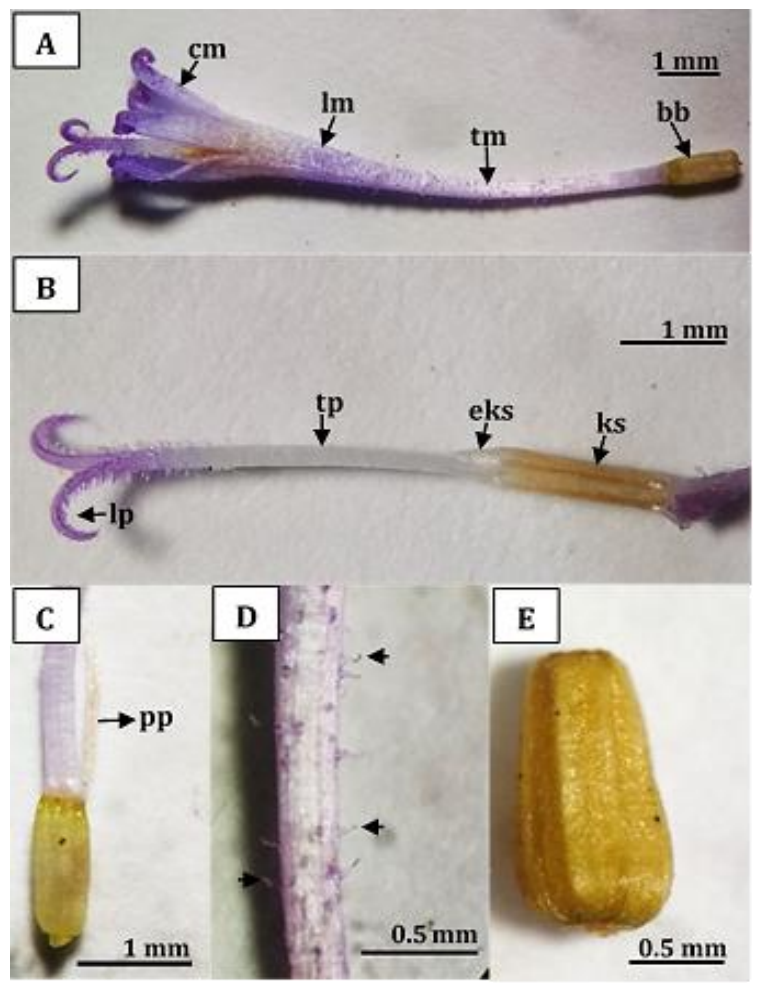

Gambar 2. Pengamatan mikroskopis organ generatif.

Keterangan: (A) Bagian utuh bunga tabung ( $\mathrm{cm}=$ cuping daun mahkota; $\mathrm{lm}=$ leher daun mahkota; $\mathrm{tm}=$ tabung daun mahkota; $\mathrm{bb}=$ bakal buah), (B) Alat kelamin bunga (lp= lengan tangkai putik; $\mathrm{tp}=$ tangkai putik; eks= embelan kepala sari; ks= kepala sari), (C) Papus (panah), (D) trikoma berkelenjar pada tabung daun mahkota (panah), dan (E) Buah longkah.

Centratherum punctatum merupakan jenis tumbuhan asing yang berasal dari Amerika Tengah, Amerika Selatan, dan Hindia Barat (Kirkman, 1981; Ghafoor, 2015). Jenis tersebut diduga masuk ke Pulau Jawa sebagai tanaman hias, karena C. punctatum telah banyak diintroduksi ke kawasan tropis melalui jalur perdagangan tanaman hias 
(Chen et al., 1999; Ghafoor, 2015; Pradheep et al., 2018). Meskipun demikian, informasi mengenai kapan $C$. punctatum diintroduksi ke Jawa untuk pertama kalinya belum diketahui secara pasti. Keberadaan jenis tersebut di Jawa belum tercatat dalam Flora of Java (Backer \& Bakhuizen van den Brink, 1965) dan revisi marga Centratherum yang disusun oleh Kirkman pada tahun 1981. Rekaman spesimen $C$. punctatum dari Jawa juga tidak ditemukan di BO. Oleh sebab itu, keberadaannya dapat ditetapkan sebagai suatu rekaman baru untuk informasi Alien Flora of Java. Selain di Jawa, keberadaan jenis ini juga telah direkam dari Samarinda (Kalimantan Timur) dan Danau Kalimpa'a, Taman Nasional Lore Lindu (Sulawesi Tengah) (Pertiwi et al., 2015; Megawati et al., 2017; Karyati \& Adhi, 2018).

Populasi meliar $C$. punctatum telah ditemukan di Kabupaten Bogor (Desa Galonggong, Kecamatan Bojong Gede) dan Kabupaten Sumedang (Desa Hegarmanah, Kecamatan Jatinangor). Populasi meliarnya kemungkinan besar berasal dari populasi yang telah ditanam sebelumnya. Jenis ini diduga telah lolos dari kultivasi dan berhasil berkembang biak tanpa bantuan manusia di alam. Penelitian terdahulu menunjukkan bahwa suku Asteraceae memiliki kecenderungan untuk lolos dari kultivasi dan berpotensi menginvasi daerah sebaran barunya (Wu \& Wang, 2005; Salvesen, 2006).

Pada penelitian ini, C. punctatum tumbuh menggulma di beberapa tipe ekosistem buatan, seperti ladang, kawasan kampus, lahan terbuka, dan tepi jalan. Hal tersebut sesuai dengan penelitian sebelumnya bahwa suatu jenis tanaman hias yang telah lolos dari kultivasi akan banyak ditemukan di kawasan yang dekat dengan aktivitas manusia (Perg et al., 2016; Mayer et al., 2017; Irsyam et al., 2020). Jenis ini berasosiasi dengan Alternanthera sessilis (L.) R.Br. ex DC. (Amaranthaceae), Bidens pilosa L. (Asteraceae), Ipomoea obscura (L.) Ker Gawl. (Convolvulaceae), dan Mimosa pudica L. (Fabaceae) di sekitar Jembatan Cincin, Jatinangor (Gambar 1-A). Selain itu, C. punctatum juga ditemukan tumbuh di antara rumpun pisang di Desa Galonggong, Bogor.
Penelitian terdahulu mengungkap bahwa penyebaran biji $C$. punctatum terjadi secara autobalokori, yaitu buah longkah yang sudah masak akan terlontar dari induknya (Debnath et al., 2017). Pemencaran jenis ini diduga tidak terjadi secara anemokori, karena bagian papus mudah rontok dari bunga dan buah longkah. Pemencaran $C$. punctatum secara autobalokori diperkuat dengan hasil pengamatan lapangan, bahwa buah longkahnya mudah terlepas dari bagian perbuahan. Selain itu, jenis ini juga diduga menyebar ke lokasi lain sebagai kontaminan dalam tanah atau lumpur yang menempel pada kendaraan, kaki manusia, dan hewan (CABI, 2014).

Centratherum punctatum telah dilaporkan lolos dari kultivasi dan ternaturalisasi di Pulau La Palma (Otto \& Verloove, 2016), Pegunungan Bvumba, Zimbabwe (Timberlake et al., 2020), India (Kamble \& Chaturvedi, 2013; Prasad \& Raveendran, 2013; Talukdar \& Deori, 2014; Bagga et al., 2018; Pradheep et al., 2018), Tripura, kaki Gunung Himalaya (Debnath et al., 2017), Taiwan (Wu et al., 2004; Wu \& Wang, 2005), Kepulauan Hawai'i (Starr et al., 2010; Imada, 2012), dan Australia (Ghafoor, 2015). Selain itu, jenis ini juga sudah ditetapkan sebagai tumbuhan asing invasif di Republik Palau (Space et al., 2009), Vietnam (Tan et al., 2012) dan Thailand (Changtragoon et al., 2010). Salah satu subspesies dari jenis ini, yaitu Centratherum punctatum Cass. ssp. fruticosum telah dilaporkan ditemukan ternaturalisasi di lahan terlantar di dekat Maldah College, India (Chowdhury \& Das, 2012) dan Taiwan (Chen et al., 1999). Berdasarkan hal tersebut, maka jenis ini dapat berpotensi invasif di Pulau Jawa.

Secara taksonomi, C. punctatum termasuk ke dalam puak Vernonieae. Puak tersebut memiliki daun yang tersusun berseling dengan pertulangan menyirip, trikoma berbentuk huruf $\mathrm{T}$ atau membintang, filari yang tersusun menyirap, daun mahkota berwarna biru hingga kemerahan atau ungu, dan cabang tangkai putik yang memanjang (Funk et al., 2009). Secara morfologi, C. punctatum dicirikan oleh helaian daun berbentuk menjorong hingga membundar 
telur sungsang (Gambar 1-C), tepi daun menggergaji tajam (Gambar 1-C), diameter perbungaan 2-2.5 cm (Gambar 1-E), filari bagian dalam tipis seperti membran (Gambar 1-E), dan tabung daun mahkota yang berkelenjar (Gambar 2-D) (Kirkman, 1981; Ghafoor, 2015).

Centratherum punctatum merupakan tambahan baru untuk anggota marga
Centratherum di Jawa. Jenis lainnya yaitu $C$. frutescens (Blume) Boerl. yang sebelumnya telah tercatat dalam Flora of Java jilid 2 (Backer \& Bakhuizen van den Brink, 1965). Jenis tersebut tumbuh pada kawasan pegunungan di Jawa (Kirkman, 1981; van Steenis, 1987). Secara morfologi, $C$. punctatum dapat dibedakan dari $C$. frutescens melalui ciri pada organ batang dan daunnya (Tabel 1) (Kirkman, 1981; Ghafoor, 2015).

Tabel 1. Perbandingan ciri morfologi $C$. frutescens dan C. punctatum

\begin{tabular}{llll}
\hline No & \multicolumn{1}{c}{ Ciri Morfologi } & \multicolumn{1}{c}{ C. frutescens } & \multicolumn{1}{c}{ C. punctatum } \\
\hline 1 & Permukaan batang & $\begin{array}{l}\text { Berbulu balig halus hingga } \\
\text { seperti wol }\end{array}$ & Bersusuhan \\
\hline 2 & Bentuk daun & Menjorong & $\begin{array}{l}\text { Membundar telur, melonjong, } \\
\text { menyudip, hingga membelah ketupat }\end{array}$ \\
\hline 3 & Ujung daun & Melancip & Menumpul hingga meruncing lebar \\
\hline 4 & Pangkal daun & Menumpul & Membaji hingga menirus \\
\hline 5 & Ukuran daun & $5-13 \times 1.5-3.9 \mathrm{~cm}$ & $1-8.3 \times 0.5-3.9 \mathrm{~cm}$ \\
\hline 6 & $\begin{array}{l}\text { Permukaan adaksial } \\
\text { daun }\end{array}$ & $\begin{array}{l}\text { Berbulu balig halus hingga } \\
\text { memasai }\end{array}$ & Berbulu balig \\
\hline 7 & $\begin{array}{l}\text { Permukaan abaksial } \\
\text { daun }\end{array}$ & $\begin{array}{l}\text { Berbulu balig halus hingga } \\
\text { menggimbal }\end{array}$ & Berbulu balig \\
\hline
\end{tabular}

Centratherum punctatum telah dikenal dan dimanfaatkan oleh masyarakat Sungai Ruphsa, Bangladesh, sebagai salah satu herbal tradisional. Secara fitokimia, ekstrak aqueous bagian aerial $C$. punctatum mengandung senyawa kaempferol-3glucuronide, chlorogenic acid, kaempferide, isorhamnetin-3-0-rutinoside, farnesol, cyanidin-3,5-di-0-glucoside, biochanin-1, 5Hydroxy-4'-methoxy-7-methylflavones,

ergocornine, kaempferol, feritidin, 3,4dicaffeoylquinic acid, 7-0-methylwogonin, asiaticoside, qingyangshengenin, dan turunan germacranolide (Balasubramanian \& Pemiah, 2015). Selain itu, komposisi minyak esensial yang terkandung pada $C$. punctatum didominasi oleh kelompok senyawa sesquiterpene hydrocarbon, seperti $\beta$ caryophyllene, cyclosativene, $\alpha$-copaene, trans- $\alpha$-bergamotene, (Z)- $\beta$-farnesene, $\alpha$ humulene, germacrene $D$, bicyclogermacrene, dan $\delta$-cadinene (Satyal et al., 2018). Beberapa penelitian menunjukkan potensi $C$. punctatum sebagai agen alami antimikroba, antioksidan, antiinflamasi, antiproliveratif, anticacing parasit Haemonchus placei dan penghambat aktivitas enzim HIV-1 reverse transcriptase (Pawar \& Arumugam, 2011; Marques et al., 2013; Chukwujekwu et al., 2014; Shankaran et al., 2017; Borges et al., 2019; Madhumitha et al., 2020). Jenis ini juga berpotensi untuk dikembangkan menjadi suplemen makanan bagi pasien penderita kanker (Sivasubramanian \& Brindha, 2014). Penelitian terkini mengungkap ekstrak kalus C. punctatum mampu menghambat pertumbuhan sel HeLa sebesar 28\% (Madhumitha et al., 2020).

\section{Simpulan}

Centratherum punctatum merupakan jenis asing rekaman baru untuk informasi Alien Flora of Java. Jenis tersebut diduga telah lolos dari kultivasi dan populasi meliarnya telah dikoleksi dari Desa Galonggong, Kecamatan Bojong Gede (Kabupaten Bogor) dan Desa Hegarmanah, Kecamatan Jatinangor (Kabupaten Sumedang).

\section{Ucapan Terima Kasih}


Penulis mengucapkan terima kasih kepada Kepala Pusat Penelitian Biologi dan Kepala Herbarium Bogoriense (BO) yang telah memberikan izin selama pengamatan spesimen koleksi berlangsung.

\section{Daftar Pustaka}

Andersen, M.C. 1993. Diaspore Morphology and Seed Dispersal in Several WindDispersed Asteraceae. American Journal of Botany. 80(5): 487-492.

Backer, C.A., Bakhuizen van den Brink, R.C. 1965. Flora of Java. Vol. 2. Groningen, The Netherlands: Wolters-Noordhoff N. V.

Bagga, J., Deshmukh, U.B., Rathor, O.S. 2018. A few additions to the flora of Palamu division of Jharkhand state. Bioscience Discovery. 9(2): 308-309.

Balasubramanian, C., Pemiah, B. 2015. Chromatographic profile from the aqueous extract of aerial parts of Centratherum punctatum Cass. Asian Journal of Biological and Life Sciences. 4(2) 156-163.

Bean, A.R. 2004. A new combination in Centratherum Cass. (Asteraceae). Austrobaileya. 6(4): 977-978.

Beentje, H. 2010. The Kew Plant Glossary: An illustrated dictionary of plant terms. Kew: Royal Botanic Garden.

Borges, D.G.L., Echeverria, J.T., de Oliveira, T.L., Heckler, R.P., de Freitas, M.G., Damasceno-Junior, G.A., Carollo, C.A., de Almeida Borges, F. 2019. Discovery of potential ovicidal natural products using metabolomics. PLoS ONE.14(1): e0211237.

CABI (Centre for Agriculture and Biosiences International). 2014. Centratherum punctatum (lark daisy). https://www.cabi.org/isc/datasheet /14608\#B2FBAAA8-8445046F786A6-6A25A1FF821D. Diakses 26 Agustus 2020.

Changtragoon, S., Ongprasert, P., Tangmitcharoen, S., Diloksampan, S., Luangviriyasaeng, $\quad \mathrm{V}$., Sornsathapornkul, P., Pattanakiat, S.
2010. Country Report on Forest Genetic Resources of Thailand. Thailand: Department of National Parks, Wildlife and Plant Conservation.

Chen, S.H., Wu, M.J., Li, S.M. 1999. Centratherum punctatum Cass. ssp. fruticosum, a newly naturalized sunflower species in Taiwan. Taiwania. 44(2): 299-305.

Christenhusz, M.J., Fay, M.F., Chase, M.W. 2017. Plants of The World. Kew: Royal Botanic Garden.

Chong, K.Y., Tan, H.T.W., Corlett, R.T. 2009. A checklist of the total vascular plant flora of Singapore: native, naturalised and cultivated species. Singapore: National University of Singapore.

Chowdhury, M., Das, A.P. 2012. Record of naturalization of Centratherym punctatum Cassini ssp. fruticosum (S. Vidal) K. Kirkman (Asteraceae): record of a newly naturalized species in India. Bulletin of the Botanical Society of Bengal. 66(1): 69-71.

Chukwujekwu, J.C., Ndhlala, A.R., de Kock, C.A., Smith, P.J., van Staden, J. 2014. Antiplasmodial, HIV-1 reverse transcriptase inhibitory and cytotoxicity properties of Centratherum punctatum Cass. and its fractions. South African Journal of Botany. 90: 17-19.

Debnath, A., Paul, C., Debnath, B. 2017. Eight new additions of plant species to the Flora of foot Himalayan state Tripura, North East India: Distributional range extension, geographic map and their less known ethno medicines. NeBIO. 8(4): 246-254.

Djarwaningsih, T., Sunarti, S., Kramadibrata, K. 2002. Panduan Pengolahan dan Pengelolaan Material Herbarium serta Pengendalian Hama Terpadu di Herbarium Bogoriense. Bogor: Herbarium Bogoriense-Bidang Botani Pusat Penelitian Biologi, LIPI.

Funk, V.A, Susanna, A., Stuessy, T. \& Robinson, H. 2009. Classification of Compositae. 
Dalam: Funk, V. A, Susanna, A., Stuessy, T., Bayer, R.J. (editor). Systematics, Evolution, and Biogeography of Compositae. Vienna: IAPT.

Ghafoor, A. 2015. Asteraceae: Trib. 3. Vernonieae. Dalam: Wilson, A.J.G. (editor). Flora of Australia Volume 37-Asteraceae 1. Melbourne: Australian Biological Resources Study/CSIRO Publishing.

Hind, N. 2015. Compositae (Asteraceae). Dalam: Utteridge, T. \& Bramley, G. (editor). The Kew: Tropical plant sukues identification handbook. (pp. 206-207). Kew: Royal Botanic Garden.

Imada, C.T. 2012. Hawaiian Native and Naturalized Vascular Plants Checklist. Honolulu: Bishop Museum.

Irsyam, A.S.D., Hariri, M.R. 2016. Eupatorium capillifolium (Lam.) Small ex Porter \& Britton (Asteraceae: Eupatorieae), Rekaman baru untuk Flora Jawa. AlKauniyah Journal of Biology. 9(2): 8086.

Irsyam, A.S.D., Irwanto, R.R., Dewi, A.P., Hariri, M.R. 2020. Catatan marga Pseudogynoxys (Asteraceae) di Pulau Jawa. Biotika. 18(1): 1-11.

Irsyam, A.S.D., Irwanto, R.R. 2019. Nine additional cultivated species of Asteraceae from Java. Jurnal Biodjati. 4(2): 244-251.

Kamble, R.B., Chaturvedi, A. 2013. New additions to the Flora of Nagpur District, Maharashtra - IV. Bioscience Discovery. 5(2): 160-162.

Karyati, Adhi, M.A. 2018. Jenis-jenis Tumbuhan Bawah di Hutan Pendidikan Fakultas Kehutanan Universitas Mulawarman. Samarinda: Mulawarman University Press.

Kirkman, L.K. 1981. Taxonomic revision of Centratherum and Phyllocephalum (Compositae: Vernonieae). Rhodora. 83(833): 1-24.

Laurent A. 2016. Asteraceae/Daisy Family. Dalam: Silverlight, R. (editor). The
Botanical Wall Chart. (pp. 32-43). London: Octopus Publishing Group.

Madhumitha, K.M., Anbumalarmathi, J., Sharmili, S.A., Nandhini, G., Priya, G.S. 2020. A Comparative Study of in vivo Plant and in vitro Callus Extracts of Centratherum punctatum Cass. Annual Research \& Review in Biology. 35(3):1-13.

Marques, M.C.S., Hamerski, L., Garcez, F.R., Tieppo, C., Vasconcelos, M., TorresSantos, E.C., Chang, M., Garcez, W.S. 2013. In vitro biological screening and evaluation of free radical scavenging activities of medicinal plants from the Brazilian Cerrado. Journal of Medicinal Plants Research. 7(15): 957-962.

Mayer, K., Haeuser, E., Dawson, W., Essel, F., Kreft, H., ..., \& van Kleunen, M. 2017. Naturalization of ornamental plant species in public green spaces and private gardens. Biological Invasions. 19: 3613-3627.

Megawati, M., Sulaeman, S. M., Pitopang, R. 2017. Keanekaragaman Suku Asteraceae di Sekitar Danau Kalimpa'a Kawasan Taman Nasional Lore Lindu. Natural Science: Journal of Science and Technology. 6(3): 239253.

Mollik, M.A.H., Hassan, A.I., Paul, T.K., Sintaha, M., Khaleque, H.N., Noor, F.A., Nahar, A., Seraj, S., Jahan, R., Chowdhury, M.H., Rahmatullah, M. 2010. A Survey of Medicinal Plant Usage by Folk Medicinal Practitioners in Two Villages by the Rupsha River in Bagerhat District, Bangladesh. American-Eurasian Journal of Sustainable Agriculture. 4(3): 349356.

Otto, R., Verloove, F. 2016. New xenophytes from La Palma (Canary Island, Spain), with emphasis on naturalized and (potentially) invasive species. Collectanea Botanica. 35: e001.

Pawar, N.K., Arumugam, N. 2011. Leaf extract of Centratherum punctatum exhibits 
antimicrobial, antioxidant and antiproliferative properties. Asian Journal of Pharmaceutical and Clinical Research.4(3): 71-76.

Perg, J., Sádlo, J., Petř́k, P., Danihelka, J., Chrtek, J., Hejda, M., ..., Pyšek, P. 2016. Dark side of the fence: ornamental plants as a source of wildgrowing flora in the Czech Republic. Preslia. 88: 163-184.

Pertiwi, R.H., Hendra, M., Syafrizal. 2015. Studi Palinologi Famili Asteraceae di Kebun Raya Universitas Mulawarman Samarinda (Krus). Prosiding Seminar Tugas Akhir FMIPA UNMUL 2015. 1(1): 1-7.

Pradheep, K., Pandey, A., Nayar, E.R., Soyimchiten, Ahlawat, S.P., Gupta, R. 2018. Extended naturalization records of five non-native plant species to Indian State. Indian Journal of Plant Genetic Resources. 31(1): 7277.

Prasad, K.S., Raveendran, K. 2013. Centratherum punctatum Cass. ssp. punctatum (Asteraceae) - naturalised in Kerala. Journal of Non-Timber Forest Products. 20(3): 231-232.

Redonda-Martínez, R. 2017. Diversity and distribution of the tribe Vernonieae (Asteraceae) in Mexico. Acta Botanica Mexicana. 119: 115-138.

Rugayah, Retnowati, A., Windadri, F.I, Hidayat, A. 2004. Pengumpulan Data Taksonomi. Dalam: Rugayah, E.A. Widjaja, dan Praptiwi (editor). Pedoman Pengumpulan Data Keanekaragaman Flora. Bogor: Pusat Penelitian Biologi-LIPI.

Salvesen, A.B. 2006. Escape of introduced ornamentals in Asteraceae with main focus on Tagetes patula L. in Western Ethiopia. Master Thesis, Department of Biology, University of Oslo.

Satyal, P., Hieu, H.V., Lai, D.T., Ngoc, N.T.B., Hung, N.H., Setzer, W.N. 2018. The essential oil compositions of Centratherum punctatum growing wild in Vietnam. American Journal of
Essential Oils and Natural Products. 6(2): 15-18.

Seale, M., Nakayama, N. 2020. From passive to informed: mechanical mechanisms of seed dispersal. New Phytologist. 225: 653-658.

Shankaran, K. S., Ganai, S. A., KP, A., Mahadevan, V. 2017. In silico and In vitro evaluation of the antiinflammatory potential of Centratherum punctatum Cass-A. Journal of Biomolecular Structure and Dynamics. 35(4): 765-780.

Sivasubramanian, R., Brindha, P. 2014. Centratherum punctatum Cass. - A herbal dietary supplement in the management of cancer. International Journal of Pharmacy and Pharmaceutical Sciences. 6(1): 73-74.

Space, J.C., Lorence, D.H., LaRosa, A.M. 2009. Report to the Republic of Palau: 2008 update on Invasive Plant Species. Hilo, Hawai'i: Institute of Pacific islands Forestry.

Starr, F., Starr, K., Loope, L.L. 2010. New plant records from the Hawaiian Archipelago. Bishop Museum Occasional Papers. 107: 61-68.

Talukdar, S.R., Deori, C. 2014. Centratherum punctatum Cass. subsp. punctatum (Asteraceae/Compositae), a newly naturalized species in India (South Asia). NeBIO. 5: 22-24.

Tan, D.T., Thu, P.Q., Dell, B. Invasive plant species in the National Parks of Vietnam. Forests. 3: 997-1016.

Timberlake, J., Ballings, P., de Deus Vidal, J., Wursten, B., Hyde, M., Mapaura, A., Childes, S., Palgrave, M.C., Clark, V.R. 2020. Mountains of the Mist: A first checklist for the Bvumba Mountains, Manica Highlands (ZimbabweMozambique). Phytokeys. 145: 93129.

Tjitrosoedirdjo, S.S. 2005. Inventory of the alien plant species in Indonesia. Biotropia. 25: 60-73. 
Tjitrosoedirdjo, S.S. 2007. Notes on the profile of Indonesian invasive alien plant species. Biotropia. 14(1): 62-68.

Tjitrosoedirdjo, S.S., Wahyuni, I. 2018. Rekor Baru Keberadaan Praxelis clematidea (Asteraceae) di Indonesia. Dalam: Kurniadie, D., Widayat, D., dan Umiyati, U. (editor). Prosiding Seminar Nasional XX Himpunan Ilmu Gulma Indonesia: Resistensi Gulma terhadap Herbisida dan Dampaknya terhadap Lingkungan dan Produk Pertanian (Hlm. 212217). Bogor: SEAMEO BIOTROP.

Tjitrosoedirdjo, S.S., Mawardi, I., Tjitrosoedirdjo, S. 2016. 75 Important Invasive Alien Plant Species in Indonesia. Bogor: SEAMEO BIOTROP.

van Balgooy, M.M.J. 1987. Collecting. Dalam: de Vogel, E.F. (editor). Manual of Herbarium Taxonomy Theory and Practice. Jakarta: UNESCO. van Steenis, C.G.G.J. 1972. The Mountain Flora of Java. Leiden: Brill.

van Steenis, C.G.G.J. 1987. Checklist of generic names in Malesian botany. (pp. 9). Leiden: Rijksherbarium.

Wu, S.H., Hsieh, C.F., Rejmanek, M. 2004. Catalogue of the Naturalized Flora of Taiwan. Taiwania. 49(1): 16-31.

Wu, S.H., Wang, H.H. 2005. Potential Asteraceae Invaders in Taiwan: Insights from the Flora and Herbarium Records of Casual and Naturalized Alien Species. Taiwania. 50(1): 62-70. 